Article

\title{
Preparation and Characterization of Thermo-Responsive Rod-Coil Diblock Copolymers
}

\author{
Yang-Yen Yu ${ }^{1,2, *}$, Wen-Chen Chien ${ }^{3}$ and Chia-Liang Tsai ${ }^{1}$ \\ 1 Department of Materials Engineering, Ming Chi University of Technology, No. 84, Gongzhuan Rd., \\ Taishan Dist., New Taipei City 24301, Taiwan; amyyu1005@gmail.com \\ 2 Department of Chemical and Materials Engineering, Chang Gung University, No. 259, Wenhua 1st Rd., \\ Guishan Dist., Taoyuan City 33302, Taiwan \\ 3 Department of Chemical Engineering, Ming Chi University of Technology, No. 84, Gongzhuan Rd., \\ Taishan Dist., New Taipei City 24301, Taiwan; wcchien@mail.mcut.edu.tw \\ * Correspondence: yyyu@mail.mcut.edu.tw
}

Received: 13 July 2017; Accepted: 1 August 2017; Published: 4 August 2017

\begin{abstract}
In this study, we synthesized amphiphilic poly(2,7-(9,9-dioctylfluorene))-block- $N, N-$ (diisopropylamino)ethyl methacrylate (POF- $b$-PDPMAEMA) rod-coil diblock copolymers by atom transfer radical polymerization (ATRP). The structure and multifunctional sensing properties of these copolymers were also investigated. The POF rod segment length of 10 was fixed and the PDPAEMA coil segment lengths of 90 and 197 were changed, respectively. The micellar aggregates of $\mathrm{POF}_{10}-b-\mathrm{PDPAEMA}_{90}$ rod-coil diblock copolymer in water showed a reversible shape transition from cylinder bundles to spheres when the temperature was changed from 20 to $80{ }^{\circ} \mathrm{C}$ or the $\mathrm{pH}$ was changed from 11 to 2 . The atomic force microscopy (AFM) and transmission electron microscopy (TEM) measurements indicated that the temperature had also an obvious influence on the micelle size. In addition, since $\mathrm{POF}_{10}-b-\mathrm{PDPAEMA}_{90}$ had a lower critical solution temperature, its photoluminescence (PL) intensity in water is thermoreversible. The PL spectra showed that the POF- $b$-PDPAEMA copolymer had a reversible on/off profile at elevated temperatures, and thus could be used as an on/off fluorescent indicator for temperature or $\mathrm{pH}$. The fluorescence intensity distribution of $\mathrm{pH}$ switched from "off-on" to "on-off" as the temperature increased. These results showed that the POF- $b$-PDPAEMA copolymer has a potential application for temperature and $\mathrm{pH}$ sensing materials.
\end{abstract}

Keywords: atom transfer radical polymerization; Rod-coil diblock copolymers; Thermo-reversible polymers

\section{Introduction}

The self-assembly of conjugated rod-coil block copolymers has been studied extensively towards novel structural, functional, and physical properties of supramolecular species [1-3]. The aggregation and microphase separation of such block copolymers driven by various novel functionalities of $\mathrm{p}-\mathrm{p}$ interaction through solvent selection or rigid segmentation may result in various nanosized morphologies [4-6]. Different conjugated rod-coil block copolymers have been reported in the literature, including those of thiophene [7,8], phenylene [9-11], and quinolone [12,13]. The fluorene-based rod-coil block copolymers were used in this study because of their high thermal/chemical stability and good fluorescence quantum yield [14-16]. Incorporating the coil segment into the backbone not only allows the possibility to control the electronic and optoelectronic properties, but also produces self-assembled nanostructures, such as spheres, worms, honeycombs, or linear structures [17]. Besides, the combination of the stimulus-responsive coil section and the tunable photophysical properties will result in novel multifunctional sensing materials $[18,19]$. Recently, the 
studies of synthesis, self-assembly of a dual thermal and $\mathrm{pH}$-responsive copolymer have been reported in the literature [20,21]. The micellar morphology of PDMAEMA-based coil-coil block copolymers has been also applied to biology [22-25]. The aggregation of rod-coil block copolymers in water and THF mixed solvents caused a reduction of quantum efficiency due to the formation of excimers [26-30]. However, the effects of detailed structure of rod-coil block copolymers on the multifunctional sensing characteristics and photophysical properties also needs to be explored further.

Two kinds of amphiphilic POF- $b$-PDPAEMA rod-coil diblock copolymers with different segment lengths, $\mathrm{POF}_{10}-b-\mathrm{PDPAEMA}_{90}$ and $\mathrm{POF}_{10}-b-\mathrm{PDPAEMA}_{197}$, were synthesized by atom transfer radical polymerization (ATRP) for systematic investigation in this study. Some important parameters such as solution temperature, acid-base value, and water/tetrahydrofuran ratio were used to study the surface morphology and photophysical properties of copolymers. Micellar aggregation was investigated by atomic force microscopy (AFM) and transmission electron microscopy (TEM) measurements. The photophysical properties of amphiphilic rod-coil diblock copolymer in solution were discussed by UV-Vis absorption spectra and photoluminescence (PL). The surface structure and photophysical properties of rod-coil block copolymers are related to rod/coil ratios and stimuli parameters. The results show that the surface structure and fluorescence characteristics for the amphiphilic POF- $b$-PDPAEMA rod-coil diblock copolymers can be manipulated by tuning the mixed solvent composition, temperature, and $\mathrm{pH}$.

\section{Experimental}

$\mathrm{N}, \mathrm{N}$-(Diisopropylamino) ethyl methacrylate (DPAEMA, Aldrich, 98\%, St. Louis, MO, USA) was purified on an aluminium oxide column. 1,1,4,7,7-Pentamethyldiethyl-enetriamine (Aldrich, 99\%), Copper(I) bromide (Aldrich, 99.99\%), 9,9-Dioctyl-2,7-dibromofluorene (Aldrich, 96\%), 2-bromoisobutyryl bromide, 4-bromobenzyl alcohol, anisole, sodium carbonate, tetrakis (triphenylphosphine)palladium, and $\mathrm{N}, \mathrm{N}$-dimethylacetamide sodium carbonate were used without purification. (9,9-dioctylfluorene)block-poly(2,7-(9,9-dioctylfluorene))-block- $N, N$-(Diisopropylamino)ethyl methacrylate) (POF- $b-$ PDPAEMA) amphiphilic copolymer was prepared by atom transfer radical polymerization.

First, POF-Br was prepared by Suzuki coupling [31,32]. The prepared POF-Br solid was redissolved in a THF solvent and then precipitated for purification by using methanol to obtain purer POF- $\mathrm{Br}\left(M_{\mathrm{n}}=3240\right.$ and PDI $\left.=1.31\right)$. The preparation of $\mathrm{POF}_{10}-b-\mathrm{PDPAEMA}_{90}$ is described below. Macroinitiator, PMDETA, $\mathrm{CuBr}$, and $\mathrm{N}, \mathrm{N}$-(diisopropylamino)ethyl methacrylate (DPAEMA at a mole ratio of 1:1:1:267 were mixed with an appropriate amount of anisole solvent. The mixture was stirred homogeneously at room temperature for $1 \mathrm{~h}$, and then temperature was raised to $90^{\circ} \mathrm{C}$ for $5.5 \mathrm{~h}$. Then, the obtained solution was dried in vacuum at $50{ }^{\circ} \mathrm{C}$ to obtain $\operatorname{PF}_{10}-b-\operatorname{PDPAEMA}_{90}\left(M_{\mathrm{n}}=19,200\right.$ and PDI $=1.29)$ as a brown solid (S1). The result of ${ }^{1} \mathrm{H} N M R\left(\mathrm{CDCl}_{3}, \delta(\mathrm{ppm})\right)$ for the POF- $b$-PDPAEMA copolymer was as follows: $0.81-0.93\left(3 \mathrm{H},-\mathrm{CH}_{2} \mathrm{C}\left(\mathrm{CH}_{3}\right)-\right), 1.69-1.89\left(2 \mathrm{H},-\mathrm{CH}_{2} \mathrm{C}\left(\mathrm{CH}_{3}\right)-\right), 2.32-2.43$ $\left(14 \mathrm{H},-\mathrm{N}\left(\mathrm{C}_{3} \mathrm{H}_{7}\right)_{2}\right), 2.55\left(2 \mathrm{H},-\mathrm{OCH}_{2} \mathrm{CH}_{2} \mathrm{~N}\left(\mathrm{C}_{3} \mathrm{H}_{7}\right)_{2}\right), 4.05\left(2 \mathrm{H},-\mathrm{OCH}_{2} \mathrm{CH}_{2} \mathrm{~N}-\left(\mathrm{C}_{3} \mathrm{H}_{7}\right)_{2}\right), 7.45-7.90(10 \mathrm{H}$, POF and phenyl aromatic $\mathrm{H}$ ). POF- $b$-PDPAEMA micelles were prepared in different ratios of solutions. The preparation of POF- $b$-PDPAEMA micelles using different solvent compositions is described below. POF- $b$-PDPAEMA amphiphilic copolymer was dissolved in THF. Then, $\mathrm{MeOH}$ was slowly added into solution to obtain a THF/MeOH mixed solvent solution with a desired $\mathrm{MeOH} / \mathrm{THF}$ ratio, 10, 25, 50, 75, and $90 \mathrm{wt} \%$, respectively. The concentration of POF- $b$-PDPAEMA copolymer in mixed solution was maintained at $1 \mathrm{mg} / \mathrm{mL}$. To study the thermo-responsive behavior, the POF- $b$-PDPAEMA amphiphilic copolymer solution in $\mathrm{MeOH}(1 \mathrm{mg} / \mathrm{mL})$ was heated to $30,40,50,60$, or $80^{\circ} \mathrm{C}$, respectively, and maintained temperature for $50 \mathrm{~h}$ to reach the thermodynamic equilibrium. On the other hand, the $\mathrm{pH}$ of POF- $b$-PDEAEMA amphiphilic copolymer solution was adjusting between 2 and 9 by using $\mathrm{HCl}$ and $\mathrm{NaOH}$ for different $\mathrm{pH}$ behavior studies. In each run, the solution had to stand for $50 \mathrm{~h}$ to reach equilibrium before measurement.

The chemical structure of synthesized copolymers was confirmed by Fourier transform infrared (FTIR) spectra (PerkinElmer Spectrum spectrophotometer, Waltham, MA, USA) and NMR spectra 
(Jeol EX-400 spectrometer, Tokyo, Japan). The photophysical properties of copolymer films were tested by ultraviolet-visible spectrophotometry (Jasco Model V-650, Oklahoma, OK, USA) and photoluminescence spectroscopy (Horiba Jobin Yvon Fluoromax-4 Spectro fluorometer, Tokyo, Japan). The adsorption spectra were measured in the range of $200-800 \mathrm{~nm}$ and an excitation wavelength of $450 \mathrm{~nm}$ was used in emission spectrum. Gel permeation chromatography calibrated by $0.5 \mathrm{wt} \%$ PS standard in THF with a flowrate of $1 \mathrm{~mL} / \mathrm{min}$ at $40{ }^{\circ} \mathrm{C}$ was used to measure the molecular weight distribution of copolymers. A refractive index detector (Schambeck SFD GmbH, model RI 2000, Bad Honnef, Germany) with a PLgel $5 \mu \mathrm{m}$ mixed-C and D column were used in gel permeation chromatography. Surface structure of copolymers were examined by a transmission electron microscopy (JEOL 1210) and atomic force microscope (Bruker Nanoscope DI III multimode AFM, Billerica, MA, USA) measurements under an acceleration voltage of $100 \mathrm{kV}$ and a tapping mode, respectively.

\section{Results and Discussion}

Figure 1 illustrates the variation of optical transmittance with temperature for the prepared copolymers, $\mathrm{POF}_{10}-b-\mathrm{PDPAEMA}_{197}$ and $\mathrm{POF}_{10}-b-\mathrm{PDPAEMA}_{90}$. It shows that the copolymer with a longer PDEAEMA chain length had a high transmission because of favorable solubility in water. In addition, the copolymer exhibited a lower critical solution temperatures (LCST) of $40{ }^{\circ} \mathrm{C}$. At this temperature, the optical transmission of the copolymer solution decreased, because the micelle structure of copolymers aggregated, leading to reduced transmittance. The optical transmittance decreased as the chain length of the DPAEMA segment increased. Therefore, the reduction of optical transmittance for $\mathrm{POF}_{10}-b-\mathrm{PDPAEMA}_{197}$ was more apparent than that obtained from $\mathrm{POF}_{10}-b-$ PDPAEMA $_{90}$.

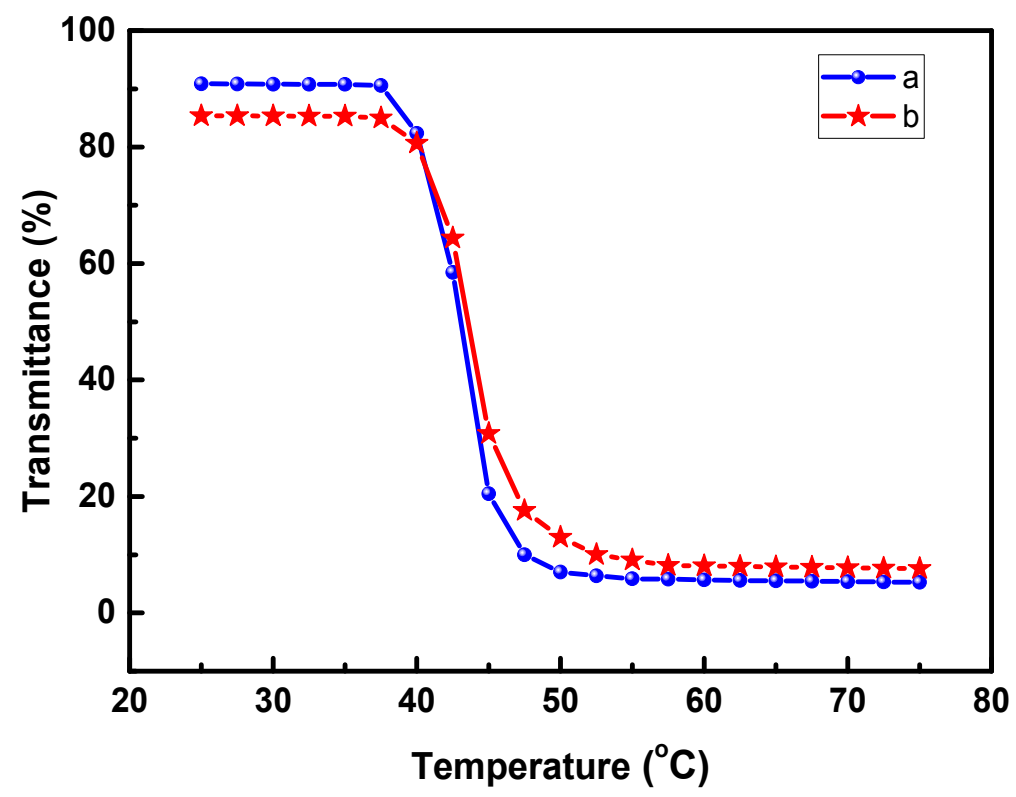

Figure 1. Variation of optical transmittance with temperature $\left(30-80^{\circ} \mathrm{C}\right)$ : (a) $\mathrm{POF}_{10}-b-\mathrm{PDPAEMA}_{197}$ and (b) POF $_{10}-b-$ PDPAEMA $_{90}$.

Figure 2 illustrates the variation of optical transmittance of $\mathrm{POF}_{10}-b-\mathrm{PDPAEMA}_{90}$ and $\mathrm{POF}_{10}-b-\mathrm{PDPAEMA}_{197}$ in water when subjected to a heating (curve a, c)-cooling (curve b, d) cycle between 30 and $80^{\circ} \mathrm{C}$, respectively. It shows the individual heating and cooling curves form a loop for $\mathrm{POF}_{10}-b-\mathrm{PDPAEMA}_{90}$ and $\mathrm{POF}_{10}-b-\mathrm{PDPAEMA}_{197}$, respectively. This hysteresis effect results from the fact that intra-chain and inter-chain hydrogen bonding forms when different segments in the copolymers aggregate together. 


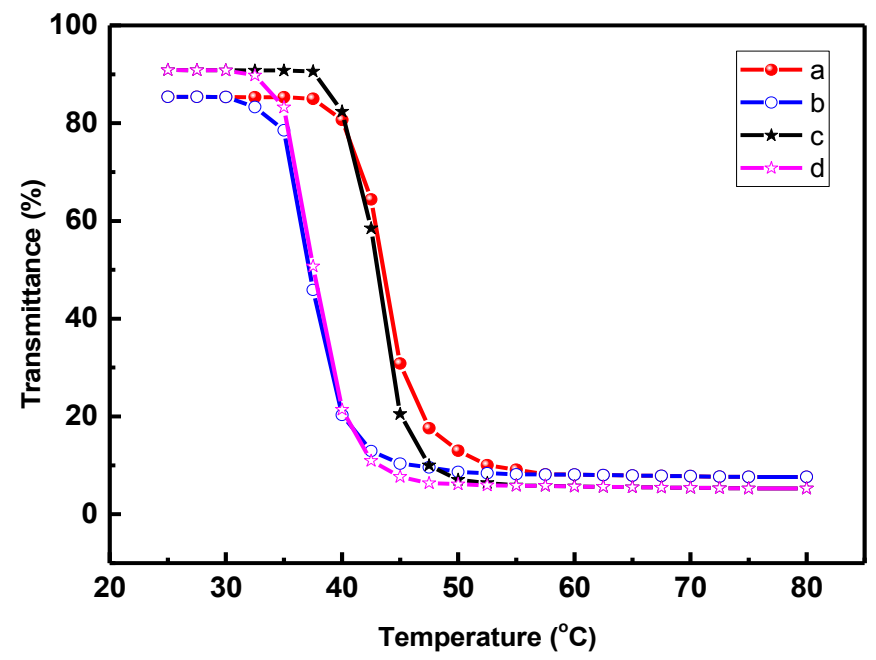

Figure 2. Variation of optical transmittance of $(\mathbf{a}, \mathbf{b})$ POF $_{10}-b-$ PDPAEMA $_{90}$ and $(\mathbf{c}, \mathbf{d})$ $\mathrm{POF}_{10}-b-\mathrm{PDPAEMA}_{197}$ in water at a heating $(\mathbf{a}, \mathbf{c})$-cooling $(\mathbf{b}, \mathbf{d})$ cycle between $30-80{ }^{\circ} \mathrm{C}$.

Such a thermo-responsive behaviors of copolymers have been reported [33]. The temperaturesensitive segment of $\mathrm{PF}_{10}-b-\mathrm{PDPAEMA} \mathrm{A}_{197}$ is longer, so its shape changes rapidly as the temperature changes, resulting in a larger slope of the change in optical transmittance and thus a narrower loop width than the $\mathrm{PF}_{10}-b-\mathrm{PDPAEMA}_{90}$ [34].

Figure 3 illustrates the PL intensity of $\mathrm{POF}_{10}-b-$ PDPAEMA $_{90}$ in water when it was subjected to a heating and cooling cycle between 30 and $80^{\circ} \mathrm{C}$. It shows that the PL intensity decreased at the heating stage and increased again at the cooling stage. The formation of intramolecular hydrogen bonding between PDPAEMA chains results in this thermo-responsive phenomenon. Heating the solution above the LCST $\left(40^{\circ} \mathrm{C}\right)$ caused the intramolecular hydrogen bonding of the PDPAEMA and the structure formed closely packed aggregates that resulted in the reduction of PL intensity [24,33]. On the contrary, cooling the solution below the LCST led to a swelling of the PDPAEMA corona in water. Consequently, the POF core can absorb more incident light and increases the light emission intensity.

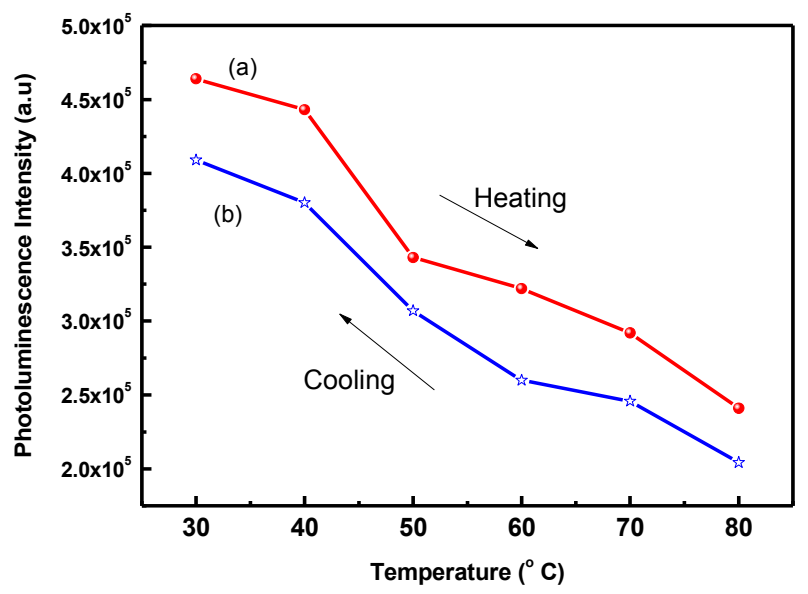

Figure 3. Photoluminescence intensity of $\mathrm{POF}_{10}-b$-PDPAEMA 90 in water at a heating-cooling cycle between 30 and $80^{\circ} \mathrm{C}$ : (a) heating (b) cooling.

Figure 4 illustrates the PL intensity of $\mathrm{POF}_{10}-b-\mathrm{PDPAEMA}_{197}$ in water when it was subjected to a heating and cooling cycle between 30 and $80^{\circ} \mathrm{C}$. Comparing Figures 3 and 4 shows that the change of fluorescence intensity for $\mathrm{POF}_{10}-b-\mathrm{PDPAEMA}_{197}$ is significantly faster than $\mathrm{POF}_{10}-b$-PDPAEMA 90 , 
because $\mathrm{POF}_{10}-b-\mathrm{PDPAEMA} \mathrm{A}_{197}$ has longer thermo-responsive chain lengths that caused a faster aggregation of micelles and thus the apparent change in photoluminescence.

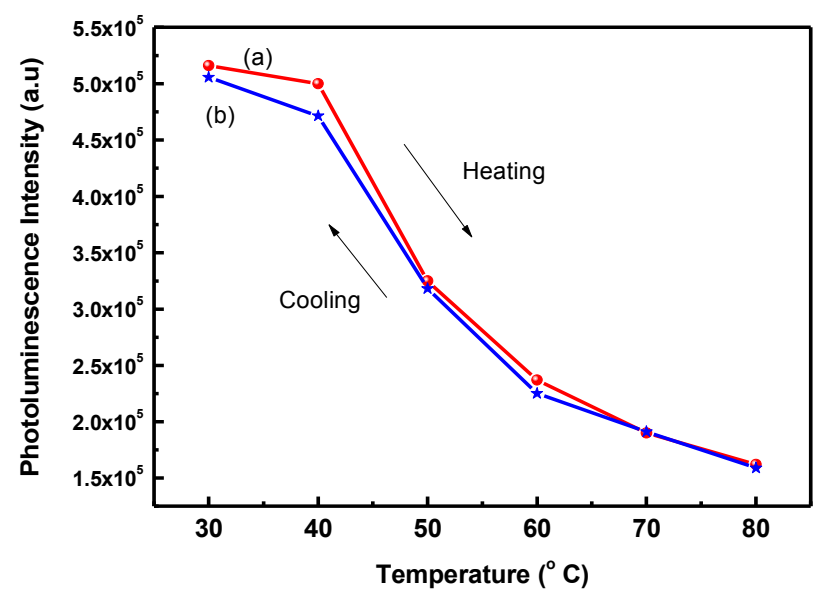

Figure 4. Photoluminescence intensity of $\mathrm{POF}_{10}-b$-PDPAEMA 197 in water at a heating-cooling cycle between 30 and $80{ }^{\circ} \mathrm{C}$ : (a) heating (b) cooling.

Figure 5 illustrates the variation in the surface structures for the $\mathrm{POF}_{10}-b-\mathrm{PDPAEMA}_{90}$ in water with temperature. It shows that the surface structure consisted of cylinder bundles at $30{ }^{\circ} \mathrm{C}$ (below the LCST), but changed to cylinders at $50{ }^{\circ} \mathrm{C}$ (above the LCST). However, the surface structure exhibited spheres at $60^{\circ} \mathrm{C}$, and the spheres aggregated at $80^{\circ} \mathrm{C}$. The described structural change of the micelles can be attributed to the variation in the hydrophilic/hydrophobic property of PDEAEMA. The highly hydrophilic PDPAEMA block showed an extended corona conformation as the temperature was below its LCST. However, as the temperature was raised above the LCST, the formation of intramolecular hydrogen bonding between the PDPAEMA chains caused a closely packed arrangement, thus water molecules were excluded from the corona.
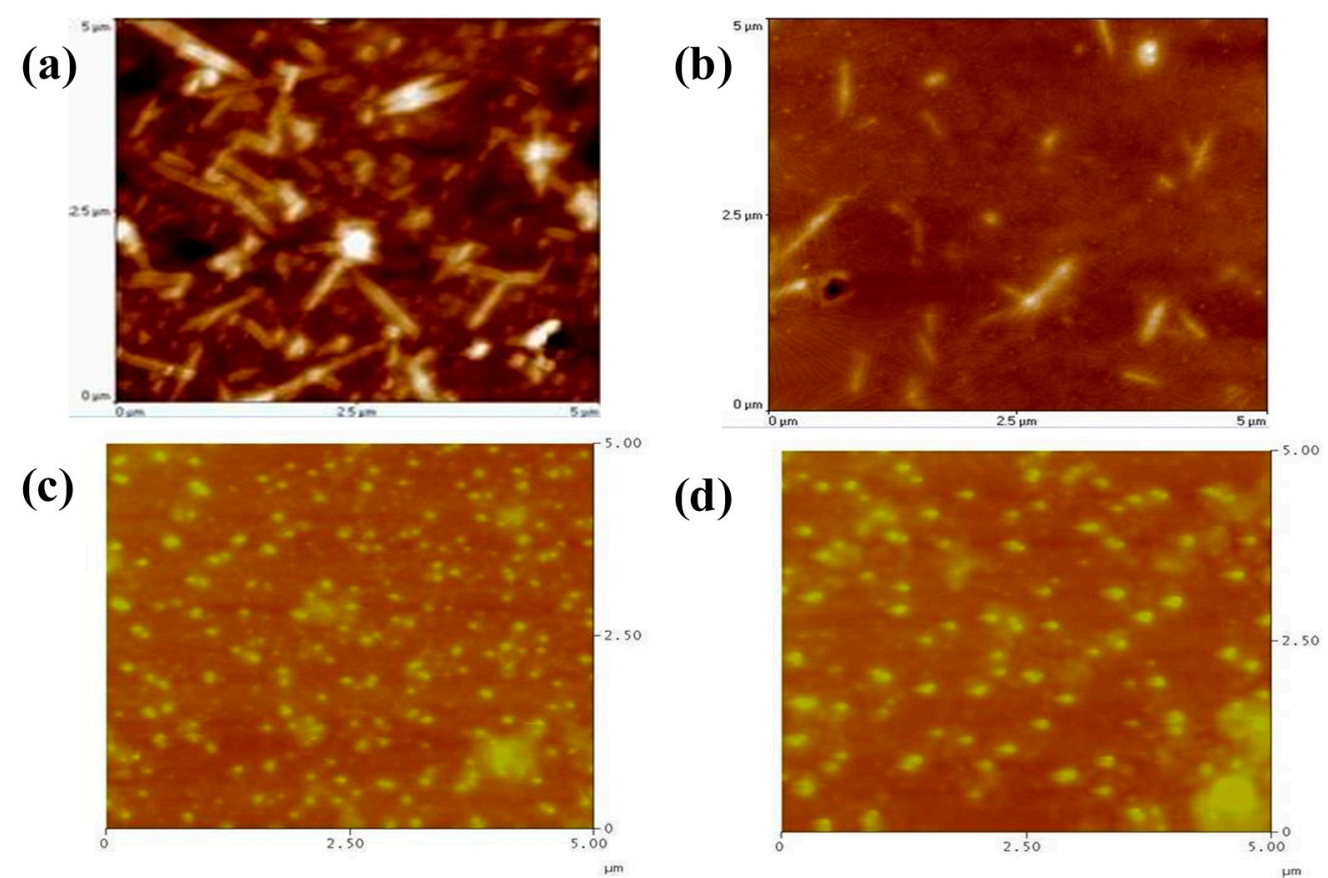

Figure 5. AFM images of $\mathrm{POF}_{10}-b-\mathrm{PDPAEMA}_{90}$ aggregates in water at temperatures of (a) $30{ }^{\circ} \mathrm{C}$, (b) $50{ }^{\circ} \mathrm{C}$, (c) $60^{\circ} \mathrm{C}$, (d) $80{ }^{\circ} \mathrm{C}$. 
Therefore, the radius of cylindrical micelles became smaller. Nevertheless, increasing the temperature from 60 to $80^{\circ} \mathrm{C}$ could enhance the intramolecular hydrogen bonding of the corona; thus, the corona became highly contracted, disrupting the POF aggregation. Figure 6 shows the variation in the surface structures for the $\mathrm{POF}_{10}-b$-PDPAEMA 197 in water with temperature. The surface structure consisted of cylinder bundles at $30^{\circ} \mathrm{C}$, but changed to spheres at $50{ }^{\circ} \mathrm{C}$ (above the LCST) because of the longer chain length of the hydrophobic PDPAEMA segment [35]. Aggregates of spherical micelles were observed at higher temperatures $\left(60-80^{\circ} \mathrm{C}\right)$ because the long hydrophobic segment reduced the colloidal stability in water, resulting in larger interconnected micelles, as shown in Figure $6 c, d$.

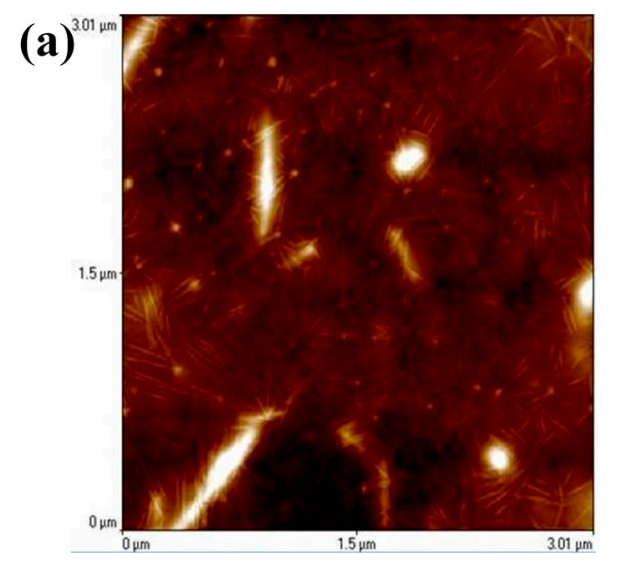

(b)

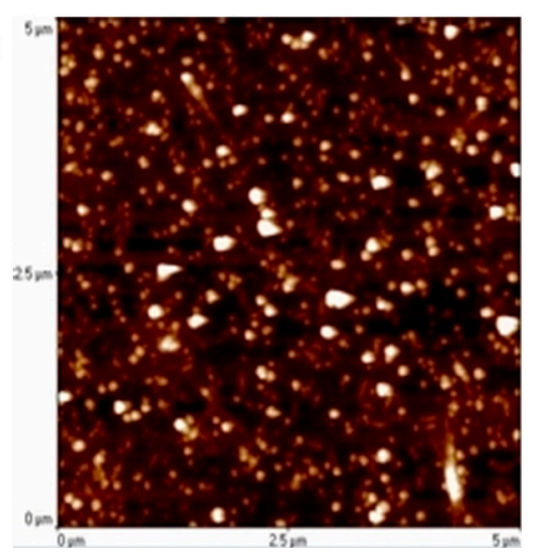

(c)

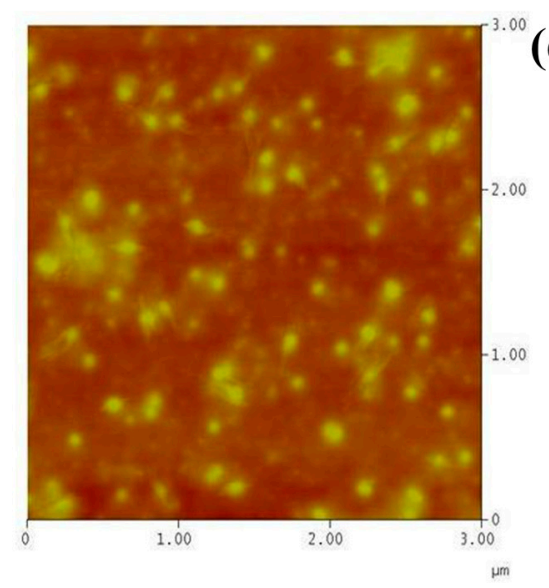

(d)

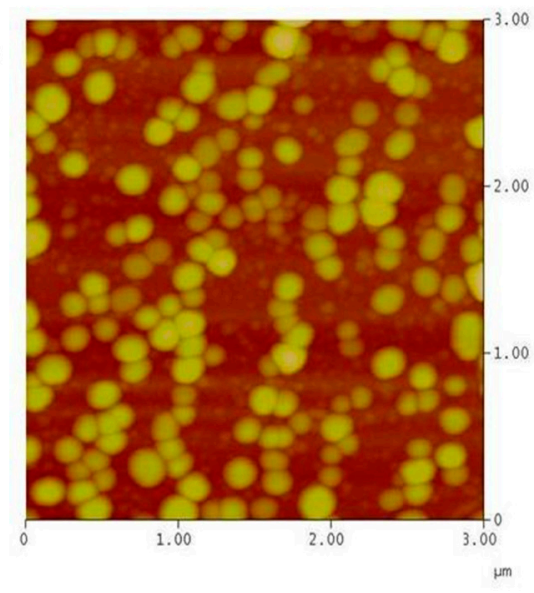

Figure 6. AFM images of $\mathrm{POF}_{10}-b-\mathrm{PDPAEMA}_{197}$ aggregates in water at temperatures of (a) $30{ }^{\circ} \mathrm{C}$, (b) $50{ }^{\circ} \mathrm{C}$, (c) $60{ }^{\circ} \mathrm{C}$, (d) $80{ }^{\circ} \mathrm{C}$.

Figure 7 illustrates the PL spectra of $\mathrm{POF}_{10}-b-\mathrm{PDPAEMA}_{90}$ in water at different solution $\mathrm{pH}$. It can be seen that the PL intensity was weak at acidic $\mathrm{pH}$, but strengthened as the $\mathrm{pH}$ increased from $\mathrm{pH}=2$ to 9 . Over $\mathrm{pH}=9$, the $\mathrm{PL}$ intensity decreased again with increasing $\mathrm{pH}$. This is because the PDPAEMA chains at acidic $\mathrm{pH}$ led to the formation of large polymer spheres so that scarcely any incident light was absorbed by the POF core, resulting in weak emission intensity. In addition, the $\mathrm{pH}$-sensitive PDPAEMA segment undergoes a decrease in the conjugate plane resulting from the aggregation of the deprotonated chains in the high $\mathrm{pH}$ environment, resulting in a decrease in the fluorescence intensity [36,37]. Figure 8 illustrates the PL intensity of $\mathrm{POF}_{10}-b-\mathrm{PDPAEMA}_{90}$ and $\mathrm{POF}_{10}-b-\mathrm{PDPAEMA}_{197}$ in water at different solution $\mathrm{pH}$. It shows that the PL intensity of $\mathrm{POF}_{10}-b-\mathrm{PDPAEMA}_{197}$ decreased at lower $\mathrm{pH}$ levels $(\mathrm{pH}=7)$ than that $(\mathrm{pH}=9)$ of $\mathrm{POF}_{10}-b$-PDPAEMA 90 , because the copolymer with a longer PDPMAEMA segment more readily undergoes aggregation at lower $\mathrm{pH}$ levels. 


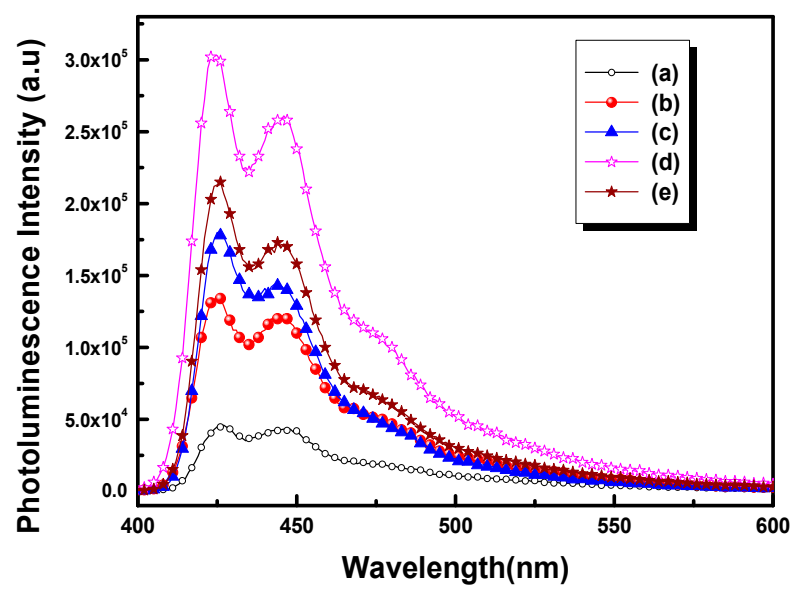

Figure 7. Photoluminescence spectra of $\mathrm{POF}_{10}-b-\mathrm{PDPAEMA}_{90}$ in water at different $\mathrm{pH}$ levels: (a) 2, (b) 5, (c) 7, (d) 9, (e) 11 .

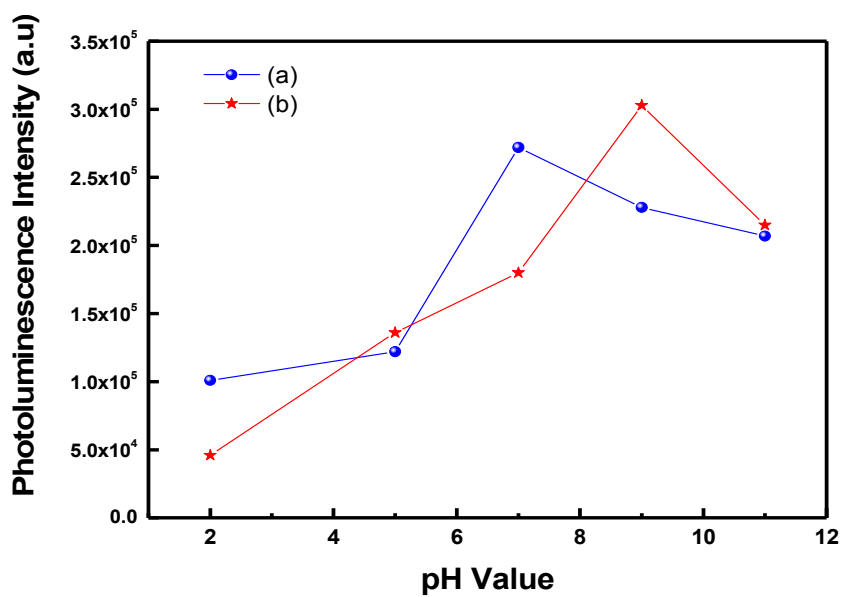

Figure 8. Variation of photoluminescence intensity of (a) $\mathrm{POF}_{10}-b-\mathrm{PDPAEMA}_{197}$ and (b) $\mathrm{POF}_{10}-b-\mathrm{PDPAEMA}_{90}$ with different $\mathrm{pH}$ levels.

Figures 9 and 10 illustrate the TEM images of the $\mathrm{POF}_{10}-b-\mathrm{PDPAEMA}_{90}$ and $\mathrm{POF}_{10}-b-$ PDPAEMA $_{197}$ micellar aggregates to show the structural change induced by $\mathrm{pH}$ variation. It shows that the spherical small micelles were observed at $\mathrm{pH}=2$, as shown in Figure $9 \mathrm{a}$. As the $\mathrm{pH}$ increased to 7 , the cylinder bundles were observed as shown in Figure $9 \mathrm{~b}$ due to the interaction between the PDPAEMA and the POF $\pi-\pi$ bond at both ends of the POF, the PDPAEMA is deprotonated and induces the aggregation, resulting in the transformation of the structure into shorter and coarse cylindrical micelles. As the $\mathrm{pH}$ value continues to rise, its morphology is transformed into a single monoclinic micelle, because the increase in the $\mathrm{pH}$ value suppresses the electrostatic repulsion of PDPAEMA, and the diameter becomes smaller into a thin cylindrical micelle as shown in Figure 9c. The result indicates that the $\mathrm{pH}$ value controls the degree of charge in the corona of the PDPAEMA block and induces swelling or shrinking because of the electrostatic repulsion. It means that the addition or removal of a proton $(\mathrm{H})$ to or from PDPAEMA has an obvious influence on the copolymer structure. As shown in Figure 10, the $\mathrm{POF}_{10}-b-\mathrm{PDPAEMA}_{197}$ copolymers show a similar structural transformation. 

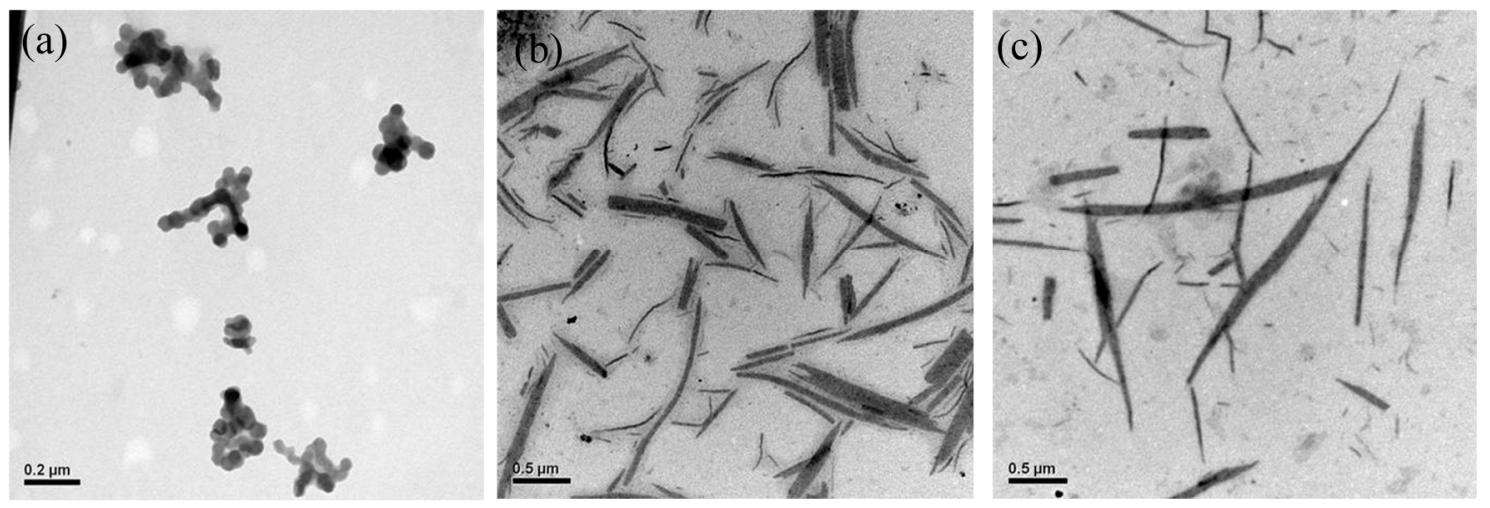

Figure 9. TEM images of $\mathrm{POF}_{10}-b-\mathrm{PDPAEMA} 90$ aggregates in water at different pH levels: (a) 2, (b) 7, (c) 11.
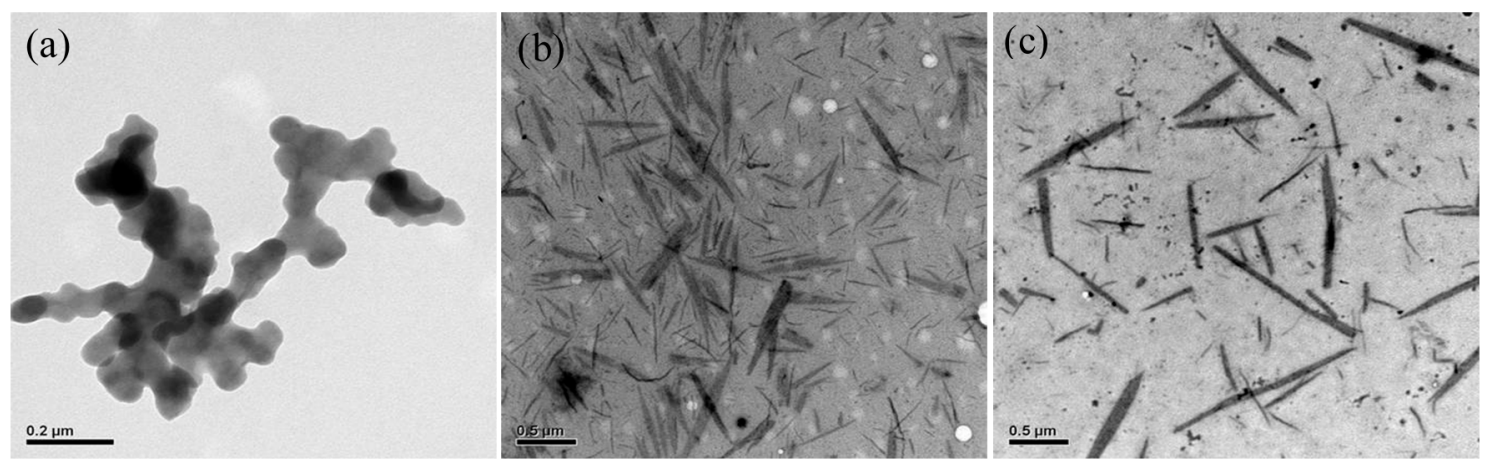

Figure 10. TEM images of $\mathrm{POF}_{10}-b-\mathrm{PDPAEMA} 197$ aggregates in water at different pH levels: (a) 2, (b) 7, (c) 11.

\section{Conclusions}

In this study, we have synthesized the POF- $b$-PDPAEMA rod-coil block copolymers that show a significant variation in their surface structure and photophysical properties with respect to the temperature and $\mathrm{pH}$. The micellar aggregates of $\mathrm{POF}_{10}-b-\mathrm{PDPAEMA}_{90}$ in water show a reversible change of surface structure from cylinder bundles to spheres under a heating-cooling cycle of $30-80{ }^{\circ} \mathrm{C}$. The LCST of $\mathrm{POF}_{10}-b-\mathrm{PDMAEMA}_{90}$ decreased with an increase in solution $\mathrm{pH}$ values due to the deprotonation of the PDPAEMA block. On the other hand, the light emission intensity for $\mathrm{POF}_{10}-b-\mathrm{PDPAEMA}_{90}$ in water was thermo-responsive, depending on its lower critical solution temperatures. It means that the prepared copolymers in this study can be applied as on/off fluorescence indicators and thus as temperature and acid-base value sensory materials, since the POF- $b$-PDPAEMA copolymer shows a stable and reversible "on-off" profile.

Supplementary Materials: Supplementary Materials are available online at www.mdpi.com/2073-4360/9/8/ 340 / s1. The GPC curves could be found in Figure S1.

Acknowledgments: The financial support provided by the National Science Council of Taiwan (Project No. MOST 104-2221-E-131-025-MY3) is greatly appreciated.

Author Contributions: Yang-Yen Yu conceived and designed the experiments; Chia-Liang Tsai performed the experiments; Yang-Yen Yu and Chia-Liang Tsai, and Wen-Chen Chien analyzed the data; Yang-Yen Yu and Wen-Chen Chien wrote the paper.

Conflicts of Interest: The authors declare no conflict of interest.

\section{References}

1. Véronique, G.; Patrick, L.; Fanny, R.; Nicolas, L.; Cyril, B.; Christoph, H.B.; Sabine, L.; Denis, V.A.; Dimitri, A.I.; Georges, H.; et al. Microstructure and Optoelectronic Properties of P3HT- $b-$ P4VP/PCBM Blends: Impact of PCBM on the Copolymer Self-Assembly. Macromolecular 2013, 46, 8824-8831. 
2. Cheng, L.L.; Chia, H.L.; Chi, C.K.; Sung, T.L.; Wen, C.C. Conjugated rod-coil block copolymers: Synthesis, morphology, photophysical properties, and stimuli-responsive applications. Prog. Polym. Sci. 2011, 36, 603-637.

3. Wen, C.W.; Ching, Y.C.; Wen, Y.L.; Wen, C.C. Stimuli-responsive conjugated rod-coil block copolymers: Synthesis, morphology, and applications. Polymer 2015, 65, A1-A16.

4. Dian, H.L.; Chia, H.L.; Ching, Y.C.; Jung, C.H.; Yu, C.C.; Wei, T.C.; Wen, C.C. Poly[2,7-(9,9-dihexylfluorene)]-block-Poly(2-vinylpyridine) Rod-Coil Star-block Copolymers: Synthesis, Micellar Structures, and Photophysical Properties. Macromol. Chem. Phys. 2011, 212, 297-304. [CrossRef]

5. Yu, Y.Y.; Hsu, C.Y.; Li, G.Y. Synthesis and Morphological Transformation of Conjugated Amphiphilic Diblock Copolymers in Mixed Solvents. J. Nanomater. 2013, 2013. [CrossRef]

6. Kumari, P.; Bera, M.K.; Malik, S.; Kuila, B.K. Amphiphilic and thermo-responsive Conjugated Block Copolymer with Its Solvent Dependent Optical and Photoluminescence Properties: Toward Sensing Applications. ACS Appl. Mater. Interfaces 2015, 7, 12348-12354. [CrossRef] [PubMed]

7. Lee, Y.H.; Yang, Y.L.; Yen, W.C.; Su, W.F.; Dai, C.A. Solution self-assembly and phase transformations of form II crystals in nanoconfined poly(3-hexyl thiophene) based rod-coil block copolymers. Nanoscale 2014, 6, 2194-2200. [CrossRef] [PubMed]

8. Vriezema, D.M.; Hoogboom, J.; Velonia, K.; Takazawa, K.; Christianen, P.; Maan, J.; Rowan, A.E.; Nolte, R.J. Vesicles and polymerized vesicles from thiophene-containing rod-coil block copolymers. Angew. Chem. 2003, 42, 772-776. [CrossRef] [PubMed]

9. Kim, Y.J.; Seo, M.; Kim, S.Y. Synthesis of Well-Defined Rod-Coil Block Copolymers Containing Trifluoromethylated Poly(phenylene oxide)s by Chain-Growth Condensation Polymerization and Atom Transfer Radical Polymerization. J. Polym. Sci. A 2010, 48, 1049-1057. [CrossRef]

10. Marsitzky, D.; Brand, T.; Geerts, Y.; Klapper, M.; Müllen, K. Synthesis of rod-coil block copolymers via end-functionalized poly(p-phenylene)s. Macromol. Rapid Commun. 1998, 19, 385-389. [CrossRef]

11. Schmücker, S.; Kuckling, D. Enhanced Preparation of Alkoxyamine-Functionalized Poly(p-phenylene)s and Their Use as Macroinitiators for the Synthesis of Stimuli-Responsive Coil-Rod-Coil Block Copolymers. Macromol. Chem. Phys. 2012, 213, 1725-1734. [CrossRef]

12. Kakogianni, S.; Kourkouli, S.N.; Andreopoulou, A.K.; Kallitsis, J.K. A versatile approach for creating hybrid semiconducting polymer-fullerene architectures for organic electronics. J. Mater. Chem. A 2014, 2, 8110-8117. [CrossRef]

13. Park, J.; Moon, M.; Seo, M.; Choi, H.; Kim, S.Y. Well-Defined Star-Shaped Rod-Coil Diblock Copolymers as a New Class of Unimolecular Micelles: Encapsulation of Guests and thermo-responsive Phase Transition. Macromolecules 2010, 43, 8304-8313. [CrossRef]

14. Tung, Y.C.; Chen, W.C. Poly[2,7-(9,9-dihexylfluorene)]-block-poly[3-(trimethoxysilyl)propyl methacrylate] (PF-b-PTMSPMA) rod-coil block copolymers: Synthesis, morphology and photophysical properties in mixed solvents. React. Funct. Polym. 2009, 69, 507-518. [CrossRef]

15. Yang, G.Z.; Chen, X.L.; Wang, L.M.; Shi, J.G.; Li, C.Z.; Liu, T. Synthesis and characterization of fluorene-based rod-coil liquid crystal polymers. Polym. Adv. Technol. 2009, 20, 104-110. [CrossRef]

16. Yao, J.H.; Mya, K.Y.; Shen, L.; He, B.P.; Li, L.; Li, Z.H.; Chen, Z.K.; Li, X.; Loh, K.P. Fluorescent nanoparticles comprising amphiphilic rod-coil graft copolymers. Macromolecules 2008, 41, 1438-1443. [CrossRef]

17. Rubatat, L.; Kong, X.; Jenekhe, S.A.; Ruokolainen, J.; Hojeij, M.; Mezzenga, R. Self-assembly of polypeptide/pi-conjugated polymer/polypeptide triblock copolymers in rod-rod-rod and coll-rod-coil conformations. Macromolecules 2008, 41, 1846-1852. [CrossRef]

18. Zhang, J.; Chen, X.F.; Wei, H.B.; Wan, X.H. Tunable assembly of amphiphilic rod-coil block copolymers in solution. Chem. Soc. Rev. 2013, 42, 9127-9154. [CrossRef] [PubMed]

19. Wu, W.C.; Tian, Y.; Chen, C.Y.; Lee, C.S.; Sheng, Y.J.; Chen, W.C.; Alex, K.Y.J. Theoretical and experimental studies on the surface structures of conjugated rod-coil block copolymer brushes. Langmuir 2007, 23, 2805-2814. [CrossRef] [PubMed]

20. Li, Y.; Zheng, X.; Wu, K.; Lu, M. Synthesis and self-assembly of a dual thermal and pH-responsive ternary graft copolymer for sustained release drug delivery. RSC Adv. 2016, 6, 2571-2581. [CrossRef]

21. Jiang, F.; Chen, S.; Cao, Z.; Wang, G. A photo, temperature, and pH responsive spiropyran-functionalized polymer: Synthesis, self-assembly and controlled release. Polymer 2016, 83, 85-91. [CrossRef] 
22. Billing, M.; Rudolph, T.; Täuscher, E.; Beckert, R.; Schacher, F.H. Synthesis and Complexation of Well-Defined Labeled Poly(N,N-dimethylaminoethyl methacrylate)s (PDMAEMA). Polymers 2015, 7, 2478-2493. [CrossRef]

23. Lin, S.T.; Tung, Y.C.; Chen, W.C. Synthesis, structures and multifunctional sensory properties of poly[2,7-(9,9-dihexylfluorene)]-block-poly[2-(dimethylamino)ethyl methacrylate] rod-coil diblock copolymers. J. Mater. Chem. 2008, 18, 3985-3992. [CrossRef]

24. Huang, K.K.; Fang, Y.K.; Hsu, J.C.; Kuo, C.C.; Chang, W.H.; Chen, W.C. Synthesis, Micellar Structures, and Multifunctional Sensory Properties of Poly(3-hexylthiophene)-block-poly(2-(dimethylamino)ethyl methacrylate) Rod-Coil Diblock Copolymers. J. Polym. Sci. A 2011, 49, 147-155. [CrossRef]

25. Huang, K.K.; Fang, Y.K.; Hsu, J.C.; Kuo, C.C.; Chang, W.H.; Chen, W.C. Thermoresponsive Luminescent Electrospun Fibers Prepared From Poly(DMAEMA-co-SA-co-StFl) Multifunctional Random Copolymers. ACS Appl. Mater. Interfaces 2010, 2, 3340-3347.

26. Bruce, C.; Javakhishvili, I.; Fogelström, L.; Carlmark, A.; Hvilsted, S.; Malmström, E. Well-defined ABA- and BAB-type block copolymers of PDMAEMA and PCL. RSC Adv. 2014, 4, 25809-25818. [CrossRef]

27. Cheng, L.; Li, Y.; Zhai, X.; Xu, B.; Cao, Z.; Liu, W. Polycation-b-Polyzwitterion Copolymer Grafted Luminescent Carbon Dots as a Multifunctional Platform for Serum-Resistant Gene Delivery and Bioimaging. ACS Appl. Mater. Interfaces 2014, 6, 20487-20497. [CrossRef] [PubMed]

28. Lu, S.; Fan, Q.L.; Chua, S.J.; Huang, W. Synthesis of conjugated-Ionic block copolymers by controlled radical polymerization. Macromolecules 2003, 36, 304-310. [CrossRef]

29. Zhang, P.; Yang, J.; Li, W.; Wang, W.; Liu, C.; Griffith, M.; Liu, W. Cationic polymer brush grafted-nanodiamond via atom transfer radical polymerization for enhanced gene delivery and bioimaging. J. Mater. Chem. 2011, 21, 7755-7764. [CrossRef]

30. Zhang, Z.; Lu, X.; Fan, Q.; Hu, W.; Huang, W. Conjugated polyelectrolyte brushes with extremely high charge density for improved energy transfer and fluorescence quenching applications. Polym. Chem. 2011, 2, 2369-2377. [CrossRef]

31. Gao, X.; Lu, P.; Ma, Y. Ultrasound-assisted Suzuki coupling reaction for rapid synthesis of polydihexylfluorene. Polymer 2014, 55, 3083-3086. [CrossRef]

32. Yao, Y.; Gao, J.; Bao, F.; Jiang, S.; Zhang, X.; Ma, R. Covalent functionalization of graphene with polythiophene through a Suzuki coupling reaction. RSC Adv. 2015, 5, 42754-42761. [CrossRef]

33. Lin, S.T.; Fuchise, K.; Chen, Y.; Sakai, R.; Satoh, T.; Kakuchi, T.; Chen, W.C. Synthesis, thermomorphic characteristics, and fluorescent properties of poly[2,7-(9,9-dihexylfluorene)]-blockpoly( $N$-isopropylacrylamide)-block-poly( $N$-hydroxyethylacrylamide) rod-coil-coil triblock copolymers. Soft Matter 2009, 5, 3761-3770. [CrossRef]

34. Sun, B.; Lin, Y.; Wu, P.; Siesler, H.W. A FTIR and 2D-IR spectroscopic study on the microdynamics phase separation mechanism of the poly( $N$-isopropylacrylamide) aqueous solution. Macromolecules 2008, 41, 1512-1520. [CrossRef]

35. Han, X.; Zhang, X.; Zhu, H.; Yin, Q.; Liu, H.; Hu, Y. Effect of Composition of PDMAEMA- $b$-PAA Block Copolymers on Their $\mathrm{pH}$ - and Temperature-Responsive Behaviors. Langmuir 2013, 29, 1024-1034. [CrossRef] [PubMed]

36. Zhuang, Z.L.; Wu, W.B.; Zhu, L.; Zhu, W.Y.; Dai, H.Q. pH-Responsive Cellulose Papers Prepared via ARGET ATRP Grafting of Poly(2-(dimethylamino)ethyl methacrylate). Acta Polym. Sin. 2015, 10, 1151-1157.

37. Liu, M.; Zhao, L.; Li, S.; Ye, H.; An, H.; Zhang, Y. pH-responsive ethylene vinyl alcohol copolymer membrane based on porphyrin supramolecular self-assembly. RSC Adv. 2016, 6, 10704-10712. [CrossRef]

(C) 2017 by the authors. Licensee MDPI, Basel, Switzerland. This article is an open access article distributed under the terms and conditions of the Creative Commons Attribution (CC BY) license (http://creativecommons.org/licenses/by/4.0/). 